\title{
Bridging the intention-behaviour gap: Planning, self-efficacy, and action control in the adoption and maintenance of physical exercise
}

\author{
FALKO F. SNIEHOTTA ${ }^{1,2}$, URTE SCHOLZ ${ }^{2}, \&$ RALF SCHWARZER $^{2}$ \\ ${ }^{1}$ University of Aberdeen and ${ }^{2}$ Freie Universität Berlin
}

\begin{abstract}
Although some people may develop an intention to change their health behaviour, they might not take any action. This discrepancy has been labelled the "intention-behaviour gap." Detailed action planning, perceived self-efficacy, and self-regulatory strategies (action control) may mediate between intentions and behaviour. This was examined in a longitudinal sample of 307 cardiac rehabilitation patients who were encouraged to adopt or maintain regular exercise. At the first time point, the predictors of intention and intention itself were assessed. Two months and four months later, the mediators and outcomes were measured. Results confirmed that all the three factors (planning, maintenance self-efficacy, and action control) served to mediate between earlier exercise intentions and later physical activity, each of them making a unique contribution. The results have implications for research on the "intention-behaviour gap," and indicate that planning, maintenance self-efficacy and action control may be important volitional variables.
\end{abstract}

Keywords: Physical exercise, self-efficacy, self-regulation, intentions, planning, action control

To better understand why and how people engage themselves in healthy behaviours and refrain from risky habits, various health behaviour models have been developed. Behavioural intentions are seen as a key ingredient in many such models (for an overview, see Abraham \& Sheeran, 2000; Armitage \& Conner, 2000; Wallston \& Armstrong, 2002; Weinstein, 2003). Whether or not the intentions are translated into action is currently regarded as a focal challenge for research. This is typically referred to as the "intention-behaviour gap," reflecting the black-box nature of the

Correspondence: Dr. Falko F. Sniehotta, School of Psychology, University of Aberdeen, College of Life Sciences and Medicine, Kings College, William Guild Building, Scotland AB24 2UB. Fax +44 (0)1224 273211.E-mail: F.sniehotta@abdn.ac.uk 
underlying psychological process that leads from intention to action. Numerous authors have suggested ways to deal with this gap. Empirical evidence has emerged, suggesting ways detailed action planning as well as perceived self-efficacy seem to be valuable proximal predictors of health actions. Moreover, self-regulation processes appear to play a role in goal pursuit. The latter can also be called action control (Abraham, Sheeran \& Johnston, 1998; Kuhl \& Fuhrmann, 1998).

The present study attempts to shed more light on these three constructs (planning, self-efficacy, action control) that may bridge the intention-behaviour gap. As a specific health behaviour domain, physical activity has been selected, although the principles should apply to all health behaviours. As a setting, cardiac rehabilitation seemed to be appropriate since physical activity is an essential health action goal for these particular patients.

\section{Psychological predictors of physical activity}

The majority of the adult population is either sedentary or not sufficiently active (Dishman \& Buckworth, 2001). In addition, most of those who begin an exercise programme fail to maintain this behaviour and relapse to inactivity within the first six months (Marcus et al., 2000). Since physical inactivity is a risk factor for coronary heart disease (CHD), the proportion of sedentary persons among CHD patients is even higher (cf. Thomson et al., 2003). CHD is a disease that develops over a long period of time and that occurs mainly in the elderly, who have developed habituated risk behaviours over many years (Krantz \& Lundgren, 2001). In cardiac rehabilitation patients, regular aerobic physical activity is associated with lower mortality, lower relapse rates, and reduced symptoms. A recent meta-analysis, found that exercise interventions led to a $31 \%$ reduction of in total cardiac mortality in CHD patients who underwent a long-term supervised exercise training programme (Jolliffe et al., 2003). It is rather the exception than a rule that habitual patterns of physical inactivity can be changed during the rehabilitation treatment. A meta-analysis showed that most patients who participated in psycho-educational programmes and who intended to change their behaviour were not very successful in doing so (Dusseldorp et al., 1999). Likewise, only $25 \%$ of the CHD patients who underwent a supervised exercise training in the rehabilitation centre had adopted a vigorous exercise programme (defined as three times a week for at least $30 \mathrm{~min}$ ) at a one-year follow-up period (Willich et al., 2001).

The question arises as to which factors may contribute to the adoption and maintenance of physical activity. Health behaviour theories such as the theory of reasoned action (TRA; Fishbein \& Ajzen, 1980), the theory of planned behaviour (TPB; Ajzen, 1991), and the protection motivation theory (PMT; Maddux, 1993; Maddux \& Rogers, 1983) emphasise the role of behavioural intentions to be the most immediate and important predictor of behaviour. Intentions are explicit decisions to act in a certain way, and they concentrate on a person's motivation towards a goal in terms of direction and intensity (Sheeran, 2002). Blanchard et al. (2002) studied exercise behaviour after coronary rehabilitation using the TPB. While attitudes and perceived behavioural control accounted for $51 \%$ of variance in intentions, intentions explained only $23 \%$ of the variance in exercise $6-10$ weeks after the rehabilitation treatment. In line with these findings, reviews of TPB applications in health behaviour domains, including exercise, come to the conclusion that the TPB variables better predict intentions than behaviour (Armitage \& Conner, 2000). It can be concluded 
that intention formation is understood well since the prediction of intentions is usually satisfactory (e.g., Garcia \& Mann, 2003). However, post-intentional processes are not yet well-understood, and, therefore, further research into this later phase of health behaviour change is needed (Ades, 2001; Blanchard, Courtneya, Rodgers, Duab \& Knapik, 2002; Donker, 2000).

Conceptual and empirical analyses of the intention-behaviour relationship have revealed that the gap between intention and behaviour can mainly be attributed to persons who intend to act, but fail to realise their intentions ("inclined abstainers," cf. Orbell \& Sheeran, 1998; Sheeran, 2002). It can be assumed that intentions play a crucial role in health-behaviour change because nonintenders are seldom found to be engaged in action. To understand fully why and how people change their behaviour, further post-intentional processes of goal pursuit must be considered and examined (Abraham et al., 1998). Many researchers have fruitfully augmented motivational prediction models, such as the TPB, TRA and PMT with volitional constructs, such as implementation intentions or attention control (Kuhl \& Fuhrmann, 1998; Milne et al., 2002; Orbell, 2003; Orbell et al., 1997; Sheeran \& Orbell, 1999). Others have suggested stages of change models (e.g., the Transtheoretical Model by Prochaska \& DiClemente, 1983). Thus, a distinction between at least one motivational phase and a subsequent volition phase may be advantageous (Heckhausen, 1991). In the motivational phase, a person develops an intention to change, based on self-beliefs, such as risk perceptions, outcome expectancies, and perceived self-efficacy. In the volitional phase, the intended behaviour must be planned, initiated and maintained, and relapses must be managed. Thereby, action planning, self-efficacy, and action control play a crucial role.

The Health Action Process Approach (HAPA; Schwarzer, 1992) provides a theoretical framework to study the motivational and the volitional processes in health behaviour change. It aims to explain the mechanisms that operate whenever individuals become motivated to change their habits, adopt and maintain new behaviours, and attempt to resist temptations and recover from setbacks. It assumes the mediation of the intention-behaviour gap by a number of volitional factors, such as planning and initiative. Before people change their habits, they develop a behavioural intention (e.g., "I intend to engage in regular exercise after my discharge from the rehab centre") based mainly on beliefs. A motivational process often starts by the emergence of a certain risk awareness (Renner \& Schwarzer, 2003; Weinstein, 2003). Although risk awareness is not a powerful predictor of behaviour (Ruiter et al., 2001; Schwarzer \& Renner, 2000), it can lead to deliberations about health behaviour change.

One also needs to understand the contingencies between one's actions and the subsequent outcomes. Outcome expectancies are beliefs about the positive and negative outcomes of alternative behaviours. An inactive person might consider physical activity to be beneficial for his or her health "if I exercise I will control my weight"), but at the same time it is very resource-demanding and exhausting ("if I exercise I will have less time for my work"). If the positive outcome expectancies (pros) outweigh the negative ones (cons), the likelihood of developing an intention to change the behaviour increases.

The third factor, perceived self-efficacy, refers to beliefs about one's own capability to accomplish a certain task by one's own actions and resources even in the face of obstacles or barriers (e.g., "I am certain that I can practice regular muscle training, even if there are time constraints"). These beliefs are critical in a novel or difficult situations 
or when strenuous self-regimens need to be adopted. There is convincing evidence that risk awareness, outcome expectancies, and self-efficacy are powerful predictors of intentions (Dzewaltowski, Noble \& Shaw, 1990; Garcia \& Mann, 2003).

Once a behavioural intention to engage in regular exercise is formed, the motivation phase is completed and the person enters the volitional phase. The intended behaviour must be planned, initiated, maintained and restarted when setbacks occur. During the volitional phase, self-regulatory efforts (Abraham \& Sheeran, 2000; Bagozzi \& Edwards, 2000; Bandura, 1997) need to be invested until the new behaviour becomes habitual.

Among the volitional processes, planning precedes the initiation of behaviour change. By planning, persons develop a mental representation of a suitable future situation ("when" and "where") and a behavioural action ("how"), which is expected to be effective for the goal pursuit to be performed in that situation. Gollwitzer (1999) calls such precise action planning, "implementation intentions" as opposed to "goal intentions." Implementation intentions promote goal attainment by helping people who are initiating a behaviour change (cf. Milne, Orbell \& Sheeran, 2002). Action planning has been proven to be a powerful predictor of health behaviour in many domains (Abraham et al., 1999; Gollwitzer \& Oettingen, 1998, for an overview). In this phase, self-efficacy determines, among others, the effort spent in initiating and maintaining the behaviour. Maintenance self-efficacy (Luszczynska \& Schwarzer, 2003) refers to the perceived capability to maintain a newly adopted behaviour, develop routines, and cope with unexpected barriers during the maintenance phase. A new health behaviour might turn out to be much more difficult to adhere to than expected, but a self-efficacious person responds confidently with better strategies, more effort, and prolonged persistence to overcome such hurdles.

\section{Action control}

Without active self-regulation, sedentary individuals would not engage themselves in a training regime. Self-regulation refers to any efforts undertaken in order to alter one's behaviour (Baumeister, Heatherton \& Tice, 1994; Carver \& Scheier, 1998). Self-monitoring, awareness of standards, and effort are conceptually distinct actions in the course of self-regulation. In the following study, we will refer to these three perceived self-regulatory processes as action control. Self-regulation failures can occur in any of these processes (Baumeister et al., 1994; Kuhl \& Fuhrmann, 1998). Nevertheless, they work only in orchestration and can therefore be thought of as indicators of one latent variable.

Action control can be seen as the most proximal volitional predictor of behaviour. Self-efficacy is assumed to promote these processes as a strategy of active mastery. Self-efficacious persons set clear goals, monitor themselves with optimism, and spend much effort in goal attainment. Likewise, it can be assumed that self-efficacy promotes action planning (Bandura, 1997).

The effects of planning on behaviour are assumed to be partly mediated by action control. Planning affects the standards for action as well as some crucial cues for self-monitoring. When self-regulatory action must be executed, persons can rely on their plans. Beyond that, a direct effect of planning on behaviour can be assumed. Some studies have provided evidence for unconscious effects of planning based on automaticity (see Gollwitzer, 1999, for an overview). According to this research, behaviour can be elicited by situational cues without active self-regulation. 


\section{Research questions}

The present study aims at examining the theoretical model outlined here in relation to the physical exercise of CHD patients four months after being discharged from the rehabilitation centre. The research design covers the three predictors within the motivation phase (risk awareness, outcome expectancies, and task self-efficacy) and the intention to be engaged in regular physical exercise. Risk awareness, outcome expectancies, and task self-efficacy are hypothesized to predict intentions. These measures are assessed during the stay in the rehabilitation centre. The study also includes planning and maintenance self-efficacy as well as action control two months after discharge and physical exercise four months after discharge. It is assumed that the three volitional variables (planning, maintenance self-efficacy, action control) will predict exercise behaviour at follow-up better than intention. The research questions are, in particular: first, whether planning fully mediates the relationship between intention and exercise; second, the effect of maintenance self-efficacy on planning and on behaviour; third, whether planning and maintenance self-efficacy add explanatory power to the model; fourth, the explanatory power and mediator status of action control. It is hypothesized that action control will partly mediate the effects of maintenance selfefficacy and planning and that their inclusion will improve the predictive power of the model. Finally, the role of previous exercise behaviour will also be addressed. While, typically, prior behaviour is the best predictor of future behaviour, this may no longer be the case if more proximal (e.g., post-intentional) constructs are included in a behaviour change model.

\section{Method}

\section{Sample and procedure}

A total of 437 in-patients with coronary heart disease (CHD) who had a medical recommendation to exercise participated in the study. They were recruited from three rehabilitation centres in Germany. They signed an informed-consent form and filled out the first questionnaire during their second week in the centre. Each participant was given a personal code to match the data from the three waves of questionnaires of the three waves in order to ensure anonymity. Two follow-up questionnaires were sent two and four months after discharge, together with a prepaid return envelope. The Time 2 follow-up questionnaire was sent back by $348(79.6 \%)$ participants. Longitudinal data collected during all the three waves were available from 307 persons $(70.3 \%$ of the participants).

The mean age of the participants was 59 years $(S D=9.98)$ with a range from 31 to 82 years, and $245(79.8 \%)$ of the participants were men. The majority were married or living with a partner $(242=78.8 \%), 12$ persons $(3.9 \%)$ were widowed, $21(6.8 \%)$ single, and $28(9.1 \%)$ divorced. Only 41 patients $(13.4 \%)$ did not have any children. Most of the participants reported a maximum of nine years of school education $(96=31.9 \%) ; 62$ participants $(20.2 \%)$ had had ten years, $77(25 \%) 12$ years, and $64(20.8 \%) 13$ years of schooling. Approximately half of the sample was currently employed $(143 ; 46.6 \%)$, and $132(43 \%)$ participants were retired. In terms of exercise behaviour before the acute treatment, $188(61.2 \%)$ of the patients had been totally inactive (i.e., zero exercise activity), whereas $119(38.8 \%)$ had been active at least once a month before their acute treatment. 


\section{Measures}

\section{Time 1}

For all constructs except for risk awareness, parcels were used to create indicators for latent variables within a structural equation approach. Parcels are sums or averages of two or more items of a construct. They have a lower error variance and are thus more reliable than the single indicators (cf. Bandalos \& Finney, 2001). Task self-efficacy, outcome expectancies, risk awareness, and intentions reflecting the motivational phase were assessed at Time 1, using the same measurement techniques as Schwarzer and Renner (2000). The item examples below are translations from German. Unless stated otherwise, all the items had a response range from 1 (not at all true) to 4 (exactly true).

Task self-efficacy was assessed by four items, for example, "I am confident that I can adjust my life to a physically active lifestyle," or "I am confident that I can be physically active at least once a week." Two parcels of two items each were used as indicators for task self-efficacy.

Outcome expectancies regarding the behaviour change were assessed with eight items. All items had the stem, "If I will exercise on a regular basis, ..." followed by positive consequences such as, ". . then I will feel balanced in my daily life," or ". . . it will be good for my blood pressure." Two parcels of four items each were used as indicators for outcome expectancies.

Risk awareness was measured by three items assessing vulnerability to coronary health problems with the stem, "If I keep my lifestyle the way it was prior to the acute treatment,..." followed by three statements concerning probable future coronary events and coronary health problems, such as, "... I will suffer from coronary health problems." The three items were used as indicators for risk awareness.

Behavioural intentions were assessed for the time after discharge from the rehabilitation centre. Participants were asked to reply to six intentional statements regarding exercise and physical activity. The stem, "I intend to..." was followed by the recommended activities, for example, "... be physically active regularly for a minimum of $30 \mathrm{~min}$ at least three times a week." Three parcels of two items each were used as indicators for behavioural intentions.

Additionally, the past exercise behaviour of the patients was assessed in terms of the average frequency per week they engaged in endurance sports (e.g., swimming, running, power-walking, biking, etc.) before their acute treatment (Phase 1 rehabilitation).

\section{Time 2}

Measures of maintenance self-efficacy, action planning, and action control were included in the second questionnaire, two months after discharge from the rehabilitation centre. Maintenance self-efficacy was assessed in accordance with Luszczynska and Schwarzer (2003): "After having started engaging in physical activity, it is important to maintain this behaviour on a long-term basis. How confident are you that you will succeed in doing so?" The item stem, "I am confident to engage in physical activity regularly on a long-term basis,..." was followed by four items concerning typical barriers that may hamper the maintenance of the behaviour, such as, "... even if I cannot see any positive changes immediately," or "... even if I am together with 
friends and relatives who are not physically active." Two parcels of two items each were used as indicators for maintenance self-efficacy.

Action planning was assessed using the same techniques as Luszczynska and Schwarzer (2003). The item stem, "I have made a detailed plan regarding..." was followed by the items (a) "... when to do my physical exercise," (b) "... where to exercise," (c) "... how to do my physical exercise," and (d) "... how often to do my physical exercise." Two parcels of two items each were used as indicators for planning.

Finally, action control was assessed by a newly developed instrument consisting of six items. Two items each addressed the different action control facets of comparative self-monitoring, awareness of standards, and self-regulatory effort. The items were introduced by the stem, "During the last four weeks, I have..." (a) "... constantly monitored myself whether I exercise frequently enough," (b) "... watched carefully that I trained for at least 30 minutes with the recommended strain per unit," (c) "... had my exercise intention often on my mind," (d) ". . always been aware of my prescribed training programme," (e) "... really tried to exercise regularly," and (f) "...tried my best to act in accordance to my standards." Three parcels that consisted of the two items of the different processes each were used as indicators for action control.

\section{Time 3}

To assess physical exercise, the participants were asked to indicate how often per week they would be engaged in different exercise activities (cf. Bernstein et al., 1998). The latent construct was composed of two indicators. Since all the patients were strongly advised to engage themselves in vigorous exercises, a check list consisting of endurance sports, such as swimming, running, power-walking, biking, etc. was summed up to an endurance sports score indicating the average workout frequency per week. The second indicator referred to activities of a similar strain as the training programme in the rehabilitation centre. The daily exercise programme in these centres consist of a bicycle-ergometer training at an individual level of strain (in $\mathrm{kW}$ ) according to the prior assessed exercise stress test for each patient. The participants were asked to report how often on average per week they trained at a strain level that corresponds in intensity to their individual level of strain in the rehabilitation centre.

Usually, continuous exercise measures have skewed distributions because the great majority of persons are completely sedentary. This was also the case in the present study. Therefore, both exercise indicators were logarithmically transformed to smoothen their distribution and approximate a normal curve (Tabachnick \& Fidell, 2001).

The means, the standard deviations, and the factor loadings for each construct are displayed in Table I.

\section{Data analysis}

Structural Equation Modelling with AMOS 4.0 (Arbuckle \& Wothke, 1999) using the Maximum Likelihood (ML) estimation was used to test the structural assumptions. The model fit was assessed by examining the comparative fit index (CFI), the root-mean-square error of approximation (RMSEA), and the Tucker-Lewis-Index (TLI). A satisfactory model fit is indicated by high CFI and TLI $(>0.90)$ and 
Table I. Means, standard deviations (SD) and factor loadings for constructs.

\begin{tabular}{|c|c|c|c|}
\hline Latent variables and their indicators & Mean (SD) & $\begin{array}{l}\text { Factor loadings within } \\
\text { constructs for Model } 3\end{array}$ & Cronbach's alpha \\
\hline Risk awareness & & & 0.92 \\
\hline Having (another) heart attack & $3.05(0.96)$ & 0.83 & \\
\hline Having great health-related problems & $2.98(0.94)$ & 0.92 & \\
\hline Suffering from coronary health problems & $3.08(0.91)$ & 0.91 & \\
\hline Outcome expectancies & & & 0.80 \\
\hline Parcel 1 & $3.39(0.53)$ & 0.80 & \\
\hline Parcel 2 & $3.58(0.46)$ & 0.92 & \\
\hline Task self-efficacy & & & 0.75 \\
\hline Parcel 1 & $3.39(0.64)$ & 0.69 & \\
\hline Parcel 2 & $3.26(0.70)$ & 0.84 & \\
\hline Intention & & & 0.82 \\
\hline Parcel 1 & $3.39(0.61)$ & 0.76 & \\
\hline Parcel 2 & $3.41(0.63)$ & 0.77 & \\
\hline Parcel 3 & $3.52(0.59)$ & 0.82 & \\
\hline Planning & & & 0.95 \\
\hline Parcel 1 & $3.07(1.01)$ & 0.97 & \\
\hline Parcel 2 & $3.25(0.89)$ & 0.97 & \\
\hline Maintenance self-efficacy & & & 0.72 \\
\hline Parcel 1 & $3.06(0.67)$ & 0.80 & \\
\hline Parcel 2 & $3.18(0.67)$ & 0.88 & \\
\hline Perceived self-regulatory processes & & & 0.91 \\
\hline Parcel: Awareness of standard & $3.14(0.86)$ & 0.77 & \\
\hline Parcel: Self-monitoring & $3.09(0.89)$ & 0.86 & \\
\hline Parcel: Effort & $3.16(0.87)$ & 0.88 & \\
\hline Exercise & & & 0.66 \\
\hline Endurance sport exercise & $1.00(0.79)$ & 0.56 & \\
\hline Rehabilitation sport exercise & $1.07(0.74)$ & 0.87 & \\
\hline
\end{tabular}

low RMSEA $(<0.08)$ (Tabachnick $\&$ Fidell, 2001). The $\chi^{2}$ of the model is a samplesize dependent index that may become distorted if the variables are not distributed normally. Therefore, it cannot be considered as a basic criterion for the model acceptance or rejection of a model. Another minimum sample discrepancy function, the $\chi^{2} / \mathrm{df}$ ratio, is suggested to be a useful criterion. Bollen and Long (1993) suggest a $\chi^{2}$ not larger than 2-5 times the degrees of freedom.

The three recursive models were tested for the formulated mediation hypothesis. To test the role of past exercise behaviour, a two-group model-comparison was examined.

\section{Model 1: Prediction of intentions and behaviour}

The first hypothetical model (see Figure 1) consisted of five latent variables covering risk awareness, outcome expectancies, and task self-efficacy as predictors of behavioural intentions representing the motivational phase, and behavioural intentions as predictor of exercise at Time 3.

Model 2: Prediction of intentions and behaviour including action planning and maintenance self-efficacy

The second model (see Figure 2) added the volitional latent constructs of maintenance self-efficacy and action planning as predictors of exercise. Paths from task 


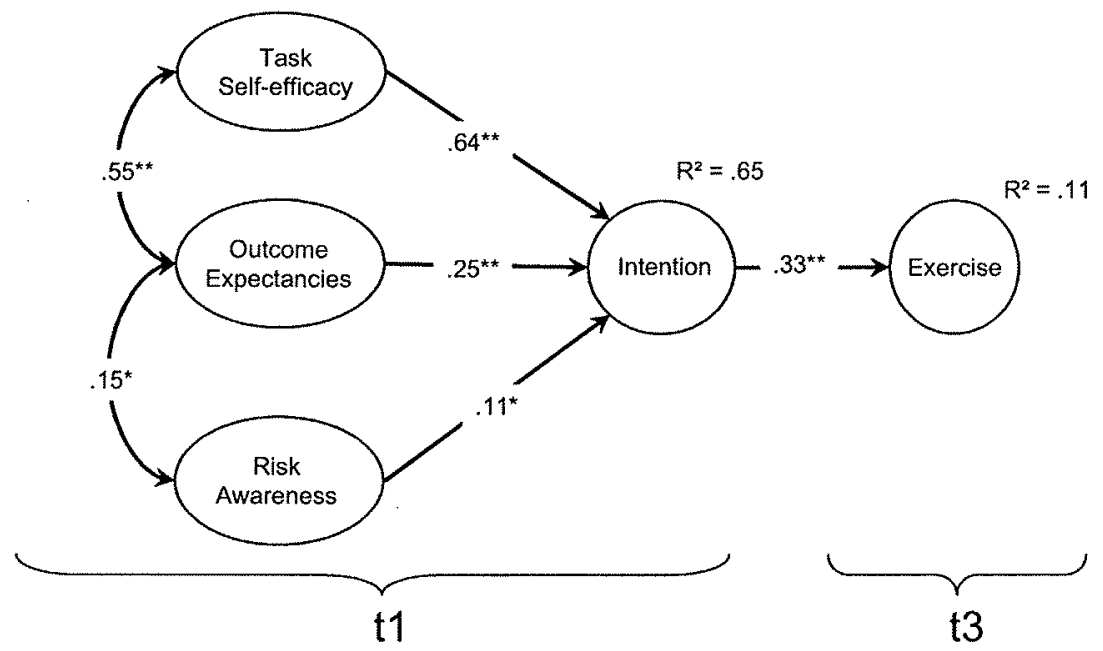

Figure 1. Model 1 with standardised regression coefficients. (Note: ${ }^{\star} p<0.05 ;{ }^{\star \star} p<0.01$.)

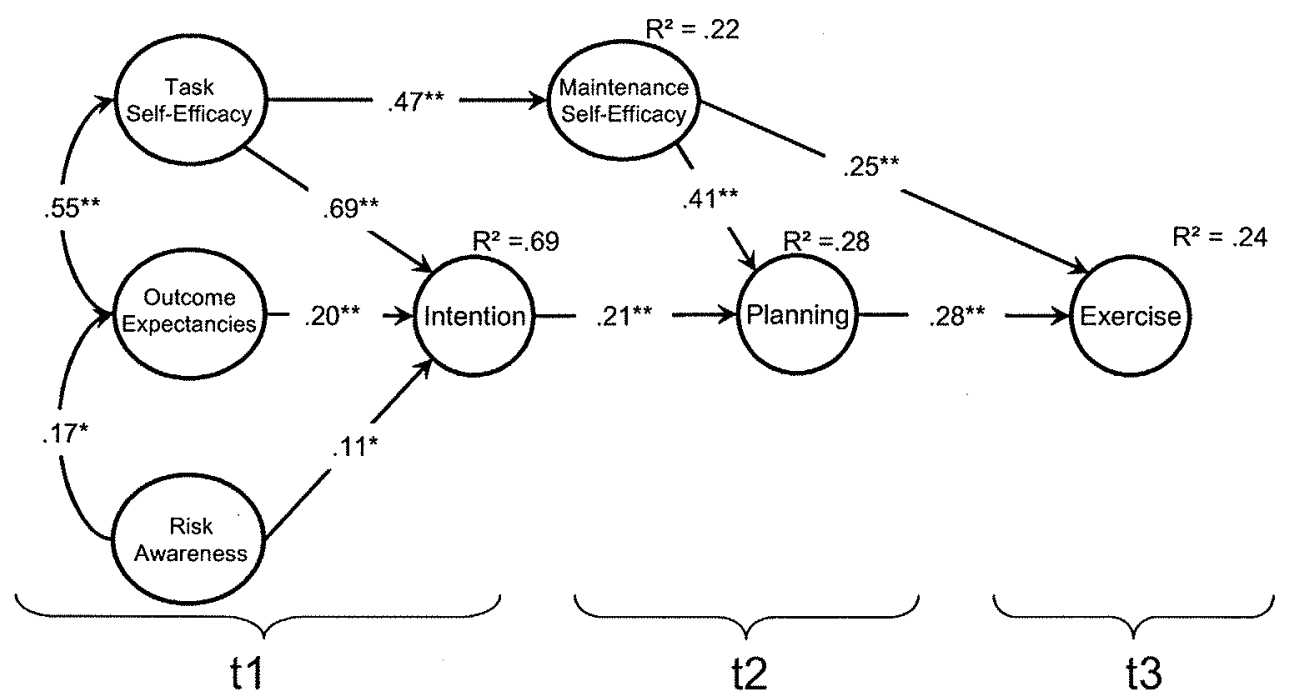

Figure 2. Model 2 with standardised regression coefficients. (Note: ${ }^{\star} p<0.05$; ${ }^{\star \star} p<0.01$.)

self-efficacy to maintenance self-efficacy and from intentions as well as from maintenance self-efficacy to action planning were specified.

Model 3: Prediction of intentions and behaviour including action planning, maintenance self-efficacy, and action control

In the third model, self-regulation was added as predictor of exercise behaviour. Intentions, maintenance self-efficacy and action planning were hypothesised to predict action control.

All the latent variables were specified with the indicators mentioned in the Method section. Measurement errors were not allowed to correlate, and, therefore, the relationships remained unbiased. The calculated hypothetical model was completely unconstrained (i.e., freely estimated). 


\section{Model 4: Two-group nested-model comparison}

In the final model, the role of past behaviour was tested. For such a test, the baseline measure is usually included as a predictor of the outcome behaviour. Thereby, the predictive power of the model for the residualized change score of behaviour is tested (Tabachnick \& Fidell, 2001). In the present study, the baseline measure was assessed retrospectively by asking the patients to report their average physical activity prior to their acute treatment. Of the participants, $61.2 \%$ reported complete inactivity prior to the acute CHD event, which resulted in an extreme violation of the requirements for most statistical procedures. Therefore, an alternative approach to examine the influence of baseline behaviour was applied. A two-group nested-model comparison between participants who reported complete inactivity at baseline and those who reported engagement in any exercise was tested on the basis of specifications of Model 3. Thereby it was examined whether this model could be assumed to be appropriate as a change model for the formerly inactive persons as well as a prediction model without control for baseline measures among participants who reported any level of former exercise.

\section{Results}

To examine whether the longitudinal subsample was representative of the initial sample, the Time 1 responses of the participants who completed all the three questionnaires $(N=307)$ were compared with those who did not $(N=130)$. No significant differences were found regarding age, sex, marital status, number of children, years of education, and work status. Likewise, participants in the longitudinal subsample did not differ from those who had filled out only the first questionnaire with regard to self-efficacy, outcome expectancies, and risk awareness. However, there was a difference in exercise intentions at baseline, $F(1,419)=5.80, p=0.016$, indicating that those who did not complete all the three questionnaires had slightly lower intentions, $M=3.30, S D=0.60$, than the participants of the longitudinal sample, $M=3.44$, $\mathrm{SD}=0.54$.

Table II presents the intercorrelations for the latent variables risk awareness, outcome expectancies, task self-efficacy, and intentions at Time 1, action planning, maintenance self-efficacy, and action control at Time 2, and exercise at Time 3. Exercise was significantly associated with all the other variables except for risk awareness, with action control being the strongest predictor of exercise.

Table II. Correlations of latent variables.

\begin{tabular}{|c|c|c|c|c|c|c|c|c|}
\hline & 1 & 2 & 3 & 4 & 5 & 6 & 7 & 8 \\
\hline 1. Risk awareness & 1.00 & & & & & & & \\
\hline 2. Outcome expectancies & $0.15^{\star}$ & 1.00 & & & & & & \\
\hline 3. Task self-efficacy & -0.09 & $0.56^{\star \star}$ & 1.00 & & & & & \\
\hline 4. Intentions & 0.15 & $0.62^{\star \star}$ & $0.77^{\star \star}$ & 1.00 & & & & \\
\hline 5. Action planning & 0.04 & $0.22^{\star \star}$ & $0.38^{\star}$ & $0.38^{\star \star}$ & 1.00 & & & \\
\hline 6. Maintenance self-efficacy & 0.09 & $0.34^{\star \star}$ & $0.42^{\star \star}$ & $0.46^{\star \star}$ & $0.49^{\star \star}$ & 1.00 & & \\
\hline 7. Action control & 0.02 & $0.26^{\star \star}$ & $0.38^{\star \star}$ & $0.40^{\star \star}$ & $0.54^{\star \star}$ & $0.46^{\star \star}$ & 1.00 & \\
\hline 8. Exercise & -0.12 & $0.21^{\star \star}$ & $0.28^{\star}$ & $0.30^{\star}$ & $0.44^{\star \star}$ & $0.42^{\star \star}$ & $0.52^{\star \star}$ & 1.00 \\
\hline
\end{tabular}

Note: ${ }^{\star} p<0.05 ;{ }^{\star} p<<0.01$. 
Modelling the predictors of exercise

Model 1: Prediction of intentions and behaviour. The first model tested the prediction of intention at baseline by the motivational variables, that is, task self-efficacy, outcome expectancies, and risk awareness, as well as the prediction of physical activity at Time 3 by Time 1 intentions. The hypothesized model fitted the data well: $\mathrm{CFI}=0.99, \mathrm{RMSEA}=0.04,90 \% \mathrm{CI}=0.017,0.058, \mathrm{TLI}=0.99, \chi^{2} / d f=1.47$, and $\chi^{2}=69.31, d f=47, p=0.02$.

The latent correlations of task self-efficacy with outcome expectancies, $r=0.55$, $p<0.01$, and of outcome expectancies with risk awareness, $r=0.15, p<0.01$, were significant. No significant association of task self-efficacy with risk awareness occurred. Task self-efficacy, $\beta=0.63, p<0.01$, outcome expectancies, $\beta=0.25, p<0.01$, and risk awareness, $\beta=0.11, p=0.04$, were significant predictors of intentions, with task self-efficacy having the strongest effect on intentions. The predictors specified in this model explained $65 \%$ of variance in intentions. In turn, intentions predicted exercise behaviour at Time 3 significantly, $\beta=0.33, p<0.01$, and explained $11 \%$ of the variance in behaviour.

Model 2: Prediction of intentions and behaviour including action planning and maintenance self-efficacy. In Model 2 (see Figure 2), maintenance self-efficacy and action planning as volitional variables were added. Action planning was specified as a mediator of the intention-behaviour relationship. The fit of the model was satisfactory: CFI $=0.99$, $\mathrm{RMSEA}=0.03,90 \% \mathrm{CI}=0.012,0.046, \mathrm{TLI}=0.99, \chi^{2} / d f=1.31$, and $\chi^{2}=120.19$, $d f=92, p=0.03$.

Again, task self-efficacy and outcome expectancies were significantly correlated, $r=0.55, p<0.01$, as well as the outcome expectancies and risk awareness, $r=0.17$, $p=0.02$. No significant relationship between task self-efficacy and risk awareness resulted. The pattern of the prediction of intention stayed the same as in the first model. All the three motivational variables were significant predictors of intentions, with task self-efficacy having the strongest effect. In all, $69 \%$ of the intention to exercise variance was accounted for by the specified predictors.

As can be seen in Figure 2, intentions were a significant predictor of action planning, $\beta=0.21, p<0.01$, while action planning predicted exercise, $\beta=0.28$, $p<0.01$. The direct path from intentions to exercise turned out to be no longer significant, $\beta=0.08, p=0.30$, whereas it had been significant in Model $1, \beta=0.33$, $p<0.01$. It can therefore be concluded that the effect of intention on exercise was fully mediated by action planning (Baron \& Kenny, 1986). The maintenance selfefficacy at Time 2 was predicted by task self-efficacy at Time $1, \beta=0.47, p<0.01$. Maintenance self-efficacy, in turn, was a significant predictor of action planning, $\beta=0.41, p<0.01$, and of exercise behaviour, $\beta=0.25, p=0.01$. The amount of explained exercise variance was $24 \%$, an increase of $13 \%$ compared to Model 1 , which used intention as the only predictor of exercise behaviour.

Model 3: Prediction of intentions and behaviour including action planning, maintenance self-efficacy, and action control. Finally, in Model 3, action control was introduced (see Figure 3). Action planning and action control were specified as mediators of 


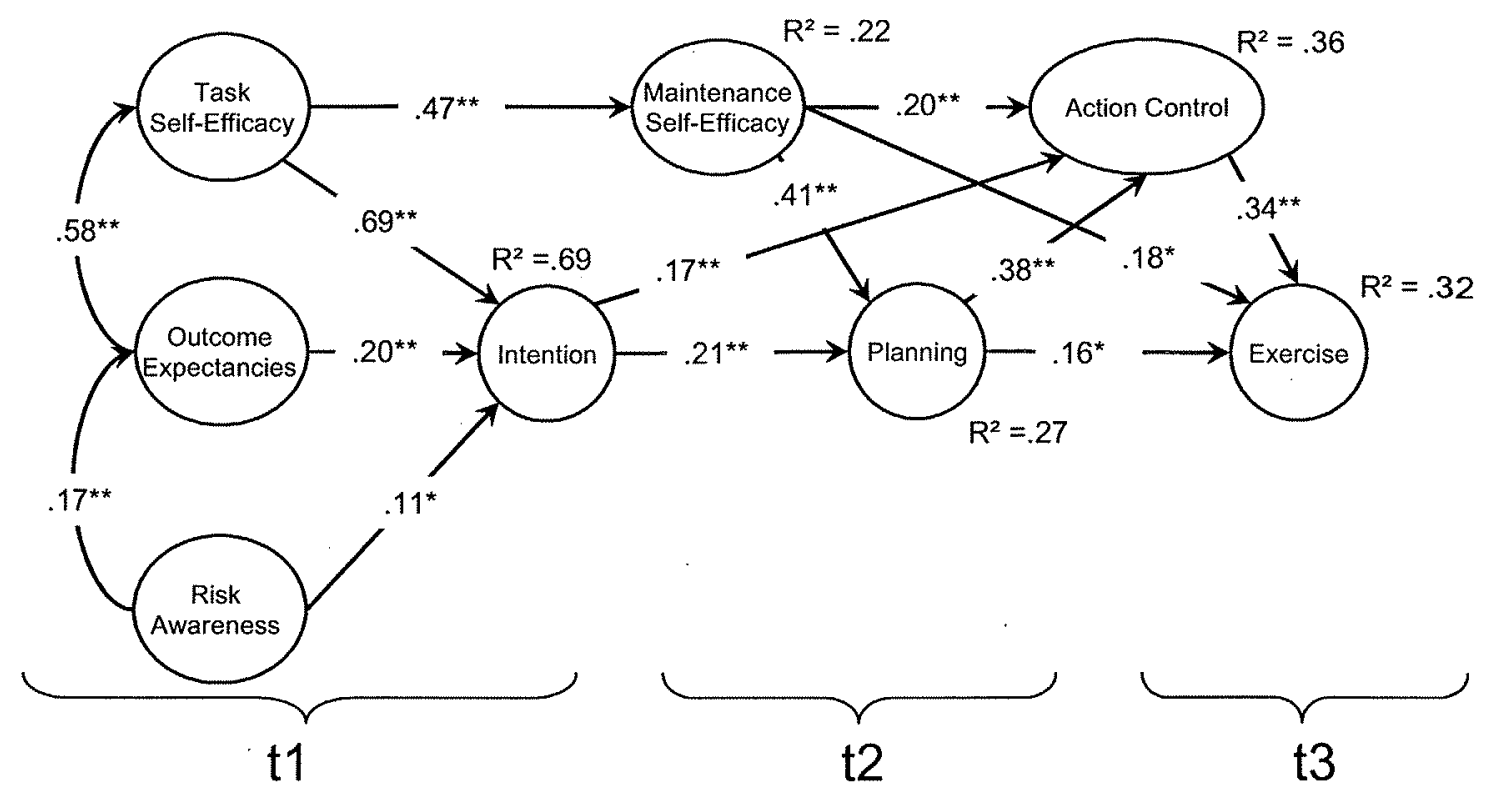

Figure 3. Model 3 with standardised regression coefficients. (Note: ${ }^{\star} p<0.05$; $\left.{ }^{\star \star} p<0.01.\right)$

the intention-exercise relationship. Action control was additionally specified to mediate the relationship between action planning and maintenance self-efficacy on the one hand, and exercise behaviour on the other. Again, the model fit indicated that the model represented the data appropriately: $C F I=0.99, R M S E A=0.02$, $90 \% \mathrm{CI}=0.000,0.038, \mathrm{TLI}=0.99, \chi^{2} / d f=1.18, \quad$ and $\chi^{2}=160.41, d f=136$, $p=0.08$. The latent correlations between the motivational variables as well as the prediction of intention by these constructs and the explained variance in intention were equal to Model 2.

The full mediation of the direct effect of intention on exercise behaviour persisted, as intention predicted both action planning, $\beta=0.21, p<0.01$, and self-regulation, $\beta=0.17, p=0.01$, and the direct path to exercise was almost zero, $\beta=0.02$, $p=0.79$. Action control had the strongest direct effect on exercise behaviour, $\beta=0.34, p<0.01$, and turned out to be a mediator of action planning and maintenance self-efficacy. However, full mediation did not occur, as action planning and maintenance self-efficacy still had significant direct effects on exercise behaviour at Time 3, albeit lower than in Model 2, $\beta=0.16, p=0.05$; and $\beta=0.18, p=0.03$, respectively. The explained variance in exercise was $R^{2}=32 \%$. This is another increase of $8 \%$ explained variance, as compared to Model 2 , which was due to the inclusion of action control. The indirect effects of intention, measured at Time 1 , should not be ignored. The total effect of intention on behaviour was still 0.09 , which is high, although lower than the direct effects of the three more proximal volitional mediators.

Two-group nested-model comparison. A two-group nested-model comparison aimed at testing whether Model 3 is an appropriate model for behaviour prediction without baseline control as well as for behavioural change. Participants who reported complete inactivity were compared to those who had reported doing at least some exercise prior to the acute medical event. For the first group, the Time 3 measures can be interpreted as change scores. 
Table III. Two-group nested-model comparison.

\begin{tabular}{|c|c|c|c|c|c|c|}
\hline & $\chi^{2}(\mathrm{df} ; p)$ & TLI & $\begin{array}{c}\Delta \chi^{2}(\mathrm{df} ; p) \\
\text { Compared with } \\
\text { "same structure" }\end{array}$ & $\Delta$ TLI & $\begin{array}{c}\Delta \chi^{2}(\mathrm{df} ; p) \\
\text { Compared with } \\
\text { "equal factor" } \\
\text { loadings }\end{array}$ & $\triangle T$ TLI \\
\hline Same structure & $\begin{array}{c}284.15 \\
(272 ; 0.29)\end{array}$ & 0.99 & & & & \\
\hline Equal factor loadings & $\begin{array}{c}298.07 \\
(286 ; 0.30)\end{array}$ & 0.99 & $\begin{array}{c}13.92 \\
(14 ; 0.50)\end{array}$ & 0.000 & & \\
\hline $\begin{array}{l}\text { Equal factor loadings } \\
\text { and equal regression } \\
\text { weights }\end{array}$ & $\begin{array}{c}303.01 \\
(298 ; 0.41)\end{array}$ & 1.00 & $\begin{array}{c}18.86 \\
(26 ; 0.84)\end{array}$ & -0.001 & $\begin{array}{c}4.94 \\
(12 ; 0.96)\end{array}$ & 0.000 \\
\hline
\end{tabular}

Note: TLI $=$ Tucker-Lewis Index.

The three nested models were tested. Model 1 was the least restricted model, assuming only the same structure of latent variables in both the groups. Model 2 assumed equal factor loadings for both the groups (invariance model), whereas Model 3 assumed both equal factor loadings and equal regression weights. The analyses are displayed in Table III.

All the three models fitted the data well. The nonsignificant chi-square difference tests indicate that no differences between the two groups could be found. It can therefore be assumed that there are no differences in the appropriateness of the specified model between the initially completely inactive individuals and the active ones.

\section{Discussion}

The present study provides evidence for the usefulness of a model of health-behaviour change that distinguishes between a motivational and a volitional phase. Regarding the motivational phase, as well as the role of action planning and maintenance self-efficacy, the present findings tend to replicate the results of Luszczynska and Schwarzer (2003). They are also perfectly in line with the theoretical assumptions of the Health Action Process Approach (Schwarzer, 1992). This lends support to the conclusion that the model chosen is meaningful and may serve as a useful heuristic for further research on physical activity.

The relationships between the motivational measures are as expected. Self-efficacy and outcome expectancies were the most influential predictors of intentions. Together with risk awareness, all the three variables accounted for $69 \%$ of the variance in intentions. This replicates findings from other research (e.g., Garcia \& Mann, 2003; Schwarzer \& Renner, 2000).

Special attention has been paid to the mediation of the intention-behaviour relationship that has guided health behaviour research for many years. It was shown that the predictive power of intentions were weakened when post-intentional volitional processes were taken into consideration. Furthermore, the inclusion of volitional measures led to a notable increase in explained variance.

The interplay of volitional variables corresponded with the theoretical assumptions. Maintenance self-efficacy and action planning were partly mediated by action control as arguably the most proximal predictor of behaviour in the model. Beyond that, both measures predicted exercise independently. In the case of action planning, this 
supports the assumption that automatization processes can be activated by action planning cognitions, as Gollwitzer (1999) and Orbell et al. (1997) have argued. The findings from this study suggest that the beneficial effects of action planning are facilitated by both the processes of automatisation, by a direct effect on behaviour, as well as by providing an action standard as a precondition for successful selfregulation, as indicated by the indirect effect mediated by action control.

The concept of automatisation also plays a central role in understanding the underlying mechanisms assumed to explain the effects of maintenance self-efficacy. For changing habitual lifestyle patterns, as the postrehabilitation CHD patients in this study are supposed to do, active self-regulation is necessary because the habits to be overcome are strongly elicited by situational cues (Sutton, 1994). Without active control, these cues would fall back into sedentary behaviour. From this point of view, the perceived capability to maintain one's behaviour change mirrors one's optimistic belief in competent self-regulation. The effect of maintenance self-efficacy on action control is, therefore, in line with these considerations.

In the present study, the volitional variables are conceptualised as mediators. The notion of volition itself, however, suggests these factors as being moderators instead. Volitional processes should only be relevant for intenders. They are rather pointless for non-intenders. There is, indeed, evidence for a moderating role of intentions on planning (Gollwitzer, 1999). Nevertheless, participants of the present study reported, on average, high levels of behavioural intentions, with limited variance. Moderator effects are usually hard to detect in such studies (McClelland \& Judd, 1993). For motivated individuals, volitional processes mediate the effects of intentions and translate intentions into actual behaviour.

Some limitations concerning the generalisation of the present study must be addressed. It has been shown that participants in the longitudinal sample reported slightly higher behavioural intentions than those who did not complete all the questionnaires. Nevertheless, the intentions within both the groups were very high on a scale ranging from 1 to $4, M=3.30$, for dropouts; $M=3.44$ in the final sample. It can, therefore, be assumed that the sample was highly motivated in general. This research addressed volitional constructs that can help people to bridge the gap between intention and action and translate their intentions into health behaviour. Therefore, small but significant differences in motivation may be less important.

The three structural equation models confirmed some basic assumptions; all the models fitted the data satisfactorily. But it must be noted that these models need not necessarily represent only one true model, as there may be others that also fit the data. Due to the longitudinal design of this study, the empirical relationships found here are tentatively interpreted as causes and effects, based on theory and time lag, not on experimental manipulation. The design was longitudinal, but for a better understanding of the role self-regulatory cognitions in the maintenance of exercise behaviour, further studies with a longer follow-up period are desirable. The relations between risk awareness, outcome expectancies, task self-efficacy, and intentions were examined cross-sectionally. Therefore, a causal interpretation of these interrelations cannot be made. The same applies to interrelations between the volitional measures of action planning, maintenance self-efficacy, and action control. While the assessment of maintenance self-efficacy and action planning addressed actual cognitions, assessment of the action control referred to the past four weeks. This retrospective assessment was necessary because the concept of action control addresses actual 
behaviours and cognitions in the course of behaviour change rather than self-beliefs or cognitive structures. Volitional variables are more adjacent to behaviour than are motivational variables. This psychological proximity is mirrored by temporal proximity in this study. This is desirable, since cross-sectional designs are less powerful than the longitudinal ones. Intention was measured at Time 1 , volitional variables at Time 2 and behaviour at Time 3. Temporal sequence is seen as a minimum requirement when causal order cannot be achieved by better means (such as experimental manipulation). Measuring predictors and mediators at the same point in time raises doubts about the mediating mechanism. In the process models, mediators should be located between predictor and criterion to avoid disturbance by method variance which typically occurs when variables are measured at the same time. One should avoid cross-sectional designs wherever possible in favour of three points in time, when testing mediator models. Thus, the current design is appropriate for a mediator test, assuring the correct temporal order of the three sets of variables.

The findings that volitional measures mediated the intention-behaviour relationship and, thus, bridge the gap between intentions and behaviour, does not take into account the possibility of changes in intentions between Time 1 and Time 2 . According to the volition theory, maintaining one's intentions over time is a central task in self-control (Kuhl \& Fuhrmann, 1998) which is independent from motivational processes of goal setting. In this study, goal setting took place during rehabilitation, indicated by high levels of intentions. After discharge, these intentions need to be maintained to decrease personal risk. Accordingly, changes in intentions can rather be seen as the result of a volitional process than as a concurrent measure to be tested against volitional factors. More research is needed to identify determinants of changes in intentions following their initial formation over time (Sheeran, 2002).

A recent longitudinal study with post-rehabilitation CHD patients has investigated the impact of action control on intention stability (Sniehotta et al., 2004). Intentions were assessed during rehabilitation and again two months after discharge. Action control was measured on a weekly basis in the six weeks after discharge. The measures of action control accounted for more variance in intentions two months after discharge than did the baseline measure of intentions. Jointly they explained $51 \%$ of the variance in intention. Furthermore, when adjusted for action control, neither the baseline, nor the follow-up measure of intention accounted for any variance in exercise - indicating that intention stability is a proxy of volition rather than an independent process (Sniehotta et al., 2004a). The present findings have implications for interventions fostering health behaviour change. The non-compliance of cardiac patients with their prescribed training programme is a serious public health problem. This problem occurs in spite of high intentions (Blanchard et al., 2002). Earlier interventions have focused on risk communication (Ruiter et al., 2001). This traditional strategy focussing on intention-enhancing risk perceptions has not been very successful. The present research, thus, emphasises an alternative strategy to the intention-based approaches by making people aware of their coping resources, that is, their selfregulatory capabilities (Lippke et al., 2004). Thus, interventions should focus on improving participants' action planning activity, heightening their self-efficacy and fostering their action control skills. For example, keeping a diary on one's performance of planned behaviour fosters self-monitoring and the awareness of standards (Muraven et al., 1999). This facilitates the long-term behaviour changes in CHD patients following rehabilitation (Sniehotta et al., in press). 


\section{References}

Abraham, C., \& Sheeran, P. (2000). Understanding and changing health behaviour: From health beliefs to self-regulation. In P. Norman, C. Abraham, \& M. Conner (Eds.), Understanding and changing health behaviour (pp. 3-24). Amsterdam: Harwood.

Abraham, C., Sheeran, P., \& Johnston, M. (1998). From health beliefs to self-regulation: Theoretical advances in the psychology of action control. Psychology and Health, 13, 569-591.

Abraham, C., Sheeran, P., Norman, P., Conner, M., De Vries, N., \& Otten, W. (1999). When good intentions are not enough: Modeling post-intention cognitive correlates of condom use. Fournal of Applied Social Psychology, 29, 2591-2612.

Ades, P. A. (2001). Cardiac rehabilitation and secondary prevention of coronary heart disease. New England fournal of Medicine, 345, 892-902.

Ajzen, I. (1991). The theory of planned behavior. Organisational Behavior and Human Decision Processes, $50,179-211$.

Arbuckle, J. L., \& Wothke, W. (1999). Amos 4.0 user guide. Chicago: Small Waters.

Armitage, C. J., \& Conner, M. (2000). Social cognition models and health behaviour: A structured review. Psychology and Health, 15, 173-189.

Bagozzi, R. P., \& Edwards, E. A. (2000). Goal setting and goal pursuit in the regulation of body weight. In P. Norman, C. Abraham, \& M. Conner (Eds.), Understanding and changing health behaviour (pp. 261-297). Amsterdam: Harwood.

Bandalos, D. L., \& Finney, S. J. (2001). Item parceling issues in structural equation modeling. In G. A. Marcoulides, \& R. E. Shumaker (Eds.), Advanced structural equation modeling: New developments and techniques (pp. 269-296). Mahwah, NJ: Erlbaum.

Bandura, A. (1997). Self-efficacy: The exercise of control. New York: Freeman.

Baron, R. M., \& Kenny, D. A. (1986). The mediator-moderator variable distinction in social psychological research: Conceptual, strategic, and statistical considerations. Foumal of Personality and Social Psychology, 51, 1173-1182.

Baumeister, R. F., Heatherton, T. F., \& Tice, D. (1994). Losing control: How and why people fail at self-regulation. San Diego, CA: Academic Press.

Bernstein, M., Sloutskis, D., Kumanyika, S., Sparti, A., Schutz, Y., \& Morabia, A. (1998). Data-based approach for developing a physical activity frequency questionnaire. American foumal of Epidemiology, 147, 147-156.

Blanchard, C. M., Courneya, K. S., Rodgers, W. M., Daub, B., \& Knapik, G. (2002). Determinants of exercise intentions and behavior during and after phase 2 cardiac rehabilitation: An application of the theory of planned behavior. Rehabilitation Psychology, 47, 308-323.

Bollen, K., \& Long, J. (Eds.) (1993). Testing structural equation models. Thousand Oaks, CA: Sage.

Carver, C. S., \& Scheier, M. F. (1998). On the self-regulation of behavior. New York: Cambridge University Press.

Dishman, R. K., \& Buckworth, J. (2001). Exercise psychology. Champaign, IL: Human Kinetics.

Donker, F. J. S. (2000). Cardiac rehabilitation. A review of current developments. Clinical Psychology Review, 20(7), 923-943.

Dusseldorp, E., Van Elderen, T., Maes, S., Meulman, J., \& Kraaij, V. (1999). A metaanalysis of psychoeducational programs for coronary heart disease patients. Health Psychology, 18, 506-519.

Dzewaltowski, D. A., Noble, J. M., \& Shaw, J. M. (1990). Physical activity participation: Social cognitive theory versus the theories of reasoned action and planned behavior. Fournal of Sport $\mathcal{G}$ Exercise Psychology, 12, 388-405.

Fishbein, M., \& Ajzen, I. (1980). Understanding attitudes and predicting social behavior. Englewood Cliffs, NJ: Prentice Hall.

Garcia, K, \& Mann, T. (2003). From 'I wish' to 'I will': Social-cognitive predictors of behavioral intentions. foumal of Health Psychology, 8, 347-360.

Gollwitzer, P. M. (1999). Implementation intentions. Strong effects of simple plans. American Psychologist, 54, 493-503.

Gollwitzer, P. M., \& Oettingen, G. O. (1998). The emergence and implementation of health goals. Psychology and Health, 13, 687-715.

Heckhausen, H. (1991). Motivation and action. New York: Springer.

Jolliffe, J. A., Rees, K., Taylor, R. S., Thompson, D., Oldridge, N., \& Ebrahim, S. (2003). Exercise based rehabilitation for coronary heart disease (Cochrane Methodology Review). In The Cochrane Library, 4. Chichester, England: Wiley.

Krantz, D. S., \& Lundgren, N. R. (2001). Cardiovascular disorders. In D. Johnston, \& M. Johnston (Eds.), Health psychology. Comprehensive clinical psychology (Vol. 8, pp. 189-216). Amsterdam: Elsevier. 
Kuhl, J., \& Fuhrmann, A. (1998). Decomposing self-regulation and self-control: The volitional components checklist. In J. Heckhausen \& C. Dweck (Eds.), Life-span perspective on motivation and control (pp. 19-45). Mahwah, NY: Erlbaum.

Lippke, S., Ziegelmann, J. P., \& Schwarzer, R. (2004). Behavioral intentions and action plans promote physical exercise: A longitudinal study with orthopedic rehabilitation patients. Foumal of Sport and Exercise Psychology, 26, 470-483.

Luszczynska, A., \& Schwarzer, R. (2003). Planning and self-efficacy in the adoption and maintenance of breast self-examination: A longitudinal study on self-regulatory cognitions. Psychology and Health, 18, 93-108.

Maddux, J. E. (1993). Social cognitive models of health and exercise behaviour. fournal of Applied Sport Psychology, 5, 116-140.

Maddux, J. E., \& Rogers, R. W. (1983). Protection motivation and self-efficacy: A revised theory of fear appeals and attitude change. Foumal of Experimental Social Psychology, 19, 469-479.

Marcus, B. H., Dubbert, P. M., Forsyth, L. H., McKenzie, T. L., Stone, E. J., Dunn, A. L., \& Blair, S. N. (2000). Physical activity behavior change: Issues in adoption and maintenance. Health Psychology, $19,32-41$.

McClelland, G. H., \& Judd, C. M. (1993). Statistical difficulties of detecting interactions and moderator effects. Psychological Bulletin, 114, 376-390.

Milne, S., Orbell, S., \& Sheeran, P. (2002). Combining motivational and volitional interventions to promote exercise participation: Protection motivation theory and implementation intentions. British fournal of Health Psychology, 7, 163-184.

Muraven, M., Baumeister, R. F., \& Tice, D. M. (1999). Longitudinal improvement of self-regulation through practice: Building self-control strength through repeated exercise. foumal of. Social Psychology, 139, 446-457.

Orbell, S. (2003). Personality systems interactions theory and the theory of planned behaviour: Evidence that self-regulatory volitional components enhance enactment of studying behaviour. British fournal of Social Psychology, 42, 95-112.

Orbell, S., Hodgkins, S., \& Sheeran, P. (1997). Implementation intentions and the theory of planned behavior. Personality and Social Psychology Bulletin, 23, 945-954.

Orbell, S., \& Sheeran, P. (1998). "Inclined abstainers": A problem for predicting health-related behaviour. British Fournal of Social Psychology, 37, 151-165.

Prochaska, J. O., \& DiClemente, C. C. (1983). Stages and processes of self-change of smoking: Toward an integrative model of change. fournal of Consulting and Clinical Psychology, 51, 390-395.

Renner, B., \& Schwarzer, R. (2003). Social-cognitive factors in health behavior change. In J. Suls, \& K. Wallston (Eds.), Social psychological foundations of health and illness (pp. 169-196). Oxford, England: Blackwell.

Ruiter, R. A. C., Abraham, C., \& Kok, G. (2001). Scary warnings and rational precautions: A review of the psychology of fear appeals. Psychology and Health, 16, 613-630.

Schwarzer, R. (1992). Self-efficacy in the adoption and maintenance of health behaviors: Theoretical approaches and a new model. In R. Schwarzer (Ed.), Self-efficacy: Thought control of action (pp. 217-242). Washington, DC: Hemisphere.

Schwarzer, R., \& Renner, B. (2000). Social-cognitive predictors of health behavior: Action self-efficacy and coping self-efficacy. Health Psychology, 19, 487-495.

Sheeran, P. (2002). Intention-behaviour relations: A conceptual and empirical review. In $M$. Hewstone, \& W. Stroebe (Eds.), European review of social psychology (Vol. 12, pp. 1-36). Chichester, England: Wiley.

Sheeran, P., \& Orbell, S. (1999). Implementation intentions and repeated behaviour: Augmenting the predictive validity of the theory of planned behaviour. European Fournal of Social Psychology, 29, 349-369.

Sniehotta, F. F., Nagy, G., Scholz, U., \& Schwarzer, R. (2004). Action control during the first weeks of health behaviour change: $A$ longitudinal study with $C H D$ patients (Manuscript under review).

Sniehotta, F.F., Scholz, U., Schwarzer, R., Fuhrmann, B., Kiwus, U,, \& Völler, H. (in press). Long-term effects of two psychological interventions on physical exercise and self-regulation after coronary rehabilitation, International Foumal of Behavioral Medicine.

Sutton, S. R. (1994). The past predicts the future: Interpreting behaviour-behaviour relationships in social-psychological models of health behaviours. In D. R. Rutter, \& L. Quine (Eds.), Social psychology and health: European perspectives (pp. 47-70). Aldershot, England: Avebury.

Tabachnick, B. G., \& Fidell, L. S. (2001). Using multivariate statistics (4th Edn.). Boston, MA: Allyn and Bacon.

Thomson, P, D. et al. (2003). Exercise and physical activity in the prevention and treatment of atherosclerotic cardiovascular disease. Circulation, 107, 3109-3116.

Wallston, K., \& Armstrong, C. (2002). Theoretically-based strategies for health behavior change. In M. P. O'Donnell (Ed.), Health promotion in the workplace (3rd Edn., pp. 182-201). Albany, NY: Delmar. 
Weinstein, N. D. (2003). Exploring the links between risk perceptions and preventive health behavior. In J. Suls, \& K. Wallston (Eds.), Social psychological foundations of health and illness (pp. 22-53). Oxford, England: Blackwell.

Willich, S. N., Muller-Nordhorn, J., Kulig, M., Binting, S., Gohlke, H., Hahmann, H., Bestehorn, K., Krobot, K., \& Voller, H.; PIN Study Group (2001). Cardiac risk factors, medication, and recurrent clinical events after acute coronary disease; a prospective cohort study. European Heart fournal, 22, $276-279$. 